\title{
Effect of "Ginseng" administration on the structural and ultrastructural changes produced by restraint stress in the liver cells of albino rats
}

\author{
Mona A.R. Salem \\ Histology Dep., Faculty of Medicine AL. Azhar Univer (Girls)
}

\begin{abstract}
This study aimed to assess the antistress effects of "Ginseng" in cases of chronic restraint stress by studying the structural and ultrastructural changes of the liver cells.

Fifteen adult male albino rats were used. They were divided equally into 3 groups: control, stress and stress/Ginseng groups. Restraint stress was applied to both stress and stress/Ginseng groups 4 hours every other day for 4 weeks. $15 \mathrm{mg}$ Ginseng/kg/ was given to stress /Ginseng group every other day for 4weeks.
\end{abstract}

Examination of liver specimens processed for both light and electron microscopic study revealed that chronic restraint stress causes fatty degeneration which may proceed to necrosis of the liver cells. A hepatoprotectective effect of ginseng was observed.

\section{Introduction}

Stress is a force that disrupts the usual physical or psychological state. Both physical and psychological stresses have important effects on the cardiovascular system (Capel et. Al., 1983).

Chronic environmental diverse agents as exposure to cold, surgical injury, excessive muscular exercise, noise, shaking (oscillation) and restraint stresses were defined by Ceremuzyniski et al., (1991) as stressors.

Stress could be an etiological factor of some disorders as reduced activity, behavioral and endocrinal alte rations, reduced food intake, hypergl ycemia, hyperacidity and increased heart rate (Simmons et al .1990).

Restraint stress is a physical stress known to cause anxiety and emotional upset which play an important role in the mechanism of stress induced changes. Panax Ginseng has been demonstrated to suppress the development of adaptation to psychological stress (Takahashi et al., 1988).

Substances, which enhance endurance for physical and mental work, increase non specific resistance to stress during a prolonged stay in psychologically adverse habitants are called "adaptogens". Panax ginseng is well known for its antistress and adaptogenic properties. It has been used as a herbal medicine for treating many 
diseases and for enhancing physical strength (Huong et. al., 1995).

Ginseng root is a wild panax species. It contains ginseng saponins $4 \%$ as ginsenoside $\mathrm{Rb} 1,-\mathrm{Rg} 1,-\mathrm{Rd}, \mathrm{Re}$, and also ocotillol - type saponins, especially majonoside- R2 which accounts for $5.3 \%$ (Nguyen et. al., 1993).

The addition of ginseng root extract to a multivitamin base appears to produce a promising dietary supplement and improving the quality of life in a population subjected to stress of high physical and mental activity (Caso et al., 1996).

The present study aimed to study the effects exerted by chronic restraint stress on liver cells and to evaluate the expected antistress effects of Ginseng.

\section{Materials and Methods}

Fifteen adult male albino rats weighing $150-180 \mathrm{~g}$ were used. They were divided into the following groups:

(1) Control group.

(2) Stress group: the animals of this group were immobilized in restraint cages at room temperature $4 \mathrm{~h} /$ day on alternate days for 4 weeks.

(3) Stress/Ginseng group: The animals of this group were subjected to immobilization as the previous stress group one hour after the administration of $15 \mathrm{mg}$ Ginseng/ $/ \mathrm{kg}$ dissolved in distilled water every other day for 4 weeks.

At the end of the experiment, the animals were sacrificed and the liver was dissected and small liver slices were immersed in $10 \%$ neutral buffered formaline, embedded in paraffin wax, sectioned at $4 \mu$ thick and sections were stained with $\mathrm{H} \& \mathrm{E}$ stain for studying the general structure. To study the fine structure, very small liver specimens $1 \mathrm{~mm}$ thick were fixed in $3 \%$ gluteraldehyde, post fixed in $2 \%$ osmium tetraoxide, dehydrated in ethanol, cleared in propylene oxide and embedded in epon. Semithin sections were prepared, ultrathin sections were stained with uranyl acetate and lead citrate and examined by Joel 100Stransmission electron microscope.

\section{Results}

\section{(1) Control group}

\section{General structure}

The hepatic lobule consists of plates of hepatic cells which branch and anastomose. The hepatic sinusoids are located between the hepatic plates and follow their branches. In the center of each hepatic lobule is the central vein. The hepatocytes are polygonal in shape, vary in size, and contain large rounded or oval vesicular nuclei. The cells have granular acidophilic cytoplasm (fig. 1).

\section{Fine structure}

The liver cell is rich in cytoplasmic organells. Mitochondria are rod-like or rounded have a medium electron dense homogenous matrix. Abundant amount of rER is also observed. Glycogen granules from aggregates, lipid droplets are also found. The vascular pole of hepatocyte facing the blood sinusoids carries many microvilli. Space of Disse is situated between the vascular pole and the endothelial cells. The wall of the sinusoid is composed of single layer of endothelial cells containing few cell organells and Kupffer cells which bulge into the sinusoidal lumen and have the common features of phagocytic cells. The nucleus of hepatocyte is central in position, rounded in shape. The nuclear chromatin is evenly distributed and slightly condensed along the nuclear membrane. The nucleolus is easily distinguishable (figs .2A\&B). 


\section{(2) Stress group}

\section{General structure:}

Stress resulted in marked vacuolation of hepatocytes. The cells in the central zone around the central vein showed signs of necrosis. They become smaller in size with deeply stained cytoplasm and nuclei. Sometimes this area is infiltrated with mononuclear cells. The cells of the peripheral zone showed marked vacuolation of their cytoplasm (figs. 3A\&B).

\section{Fine structure}

Most hepatocytes show many lipid droplets in their cytoplasm. Their nuclei appear normal. Necrotic cells showed very small nuclei with chromatin clumping (figs.4A\&B).

\section{(3) Stress/ Ginseng group}

\section{General structure}

Ginseng administration decreased the cellular necrosis and the vacuolation observed in the cytoplasm of the hepatocytes caused by stress. The cells restore its normal appearance and become more or less as the normal cont -rol hepatocyte .The mononuclear cell infiltration was also decreased (fig. 5).

\section{Fine structure}

The hepatocytes partially retained their normal appearance. No marked detectable changes were seen (fig $6 \mathrm{~A} \& \mathrm{~B})$.

\section{Discussion}

Chronic immobilization was applied to rats on alternate days to prevent their adaptation to the same repeated chronic condition (Seckin et al., 1997).

Restraint stress is a physical stress which causes anxiety and plays an important role in the mechanism of stress induced changes (Takahashi et al., 1988).

In the present study the exposure of rats to restraint stress for 4 weeks produced central lobular necrotic areas infiltrated with mononuclear cells surrounded by markedly vacuolated cells. These findings agree with the changes reported by Sikiric et al.,(1993) who proved that the fatty changes observed in the liver cells in restraint stressed rats appear as a complex result of all events non-specifically referred to as "stress". Besides Sudo and Miki (1993) found that sever stress as immobilization causes marked changes in corticosterone, adrenaline, norad renaline and dopamine.

Yegen et al., (1990) reported that the hepatic lipids accumulate in rats exposed to prolonged immobilization presumbly due to a decreased lipolysis and a suppressed lipoprotein mobiliz ation from the liver to blood.

$$
\text { Yegen et al., (1990) and }
$$

Simmons et al., (1990) have demonstrated that restraint stress increased free radical generation and lipid peroxidation. Yegen et al., (1990) have suggested that stress also cause glutathione reduction which is of vital importance in protecting the tissues from oxidative damage. Alptekin et al., (1996) demonstrated that lipid peroxidation may play an important role in the reduction of glutathione in some tissues following acute restraint stress. Seckin et al., (1997) found that vitamin $\mathrm{C}$ levels in the liver were decreased in chronic stress.

Yoshikawa et al., (1997) found that the glycosidic fraction from the dried roots of Panax Ginseng show a protective effects on liver induce $\mathrm{d}$ by D-galactosamine and lipoplysaccharide.

The same authers in 1998 also found that the methamolic extract of 
Amercan Ginseng exhibit a protective effect on liver injury induced by Dgalactosamine and lipopoly-saccharide.

The hepatotoxicity seems to be a consequence of the formation of haloalkane free radicals which produce their damaging effects either directly or by inhibiting peroxidation of unsat urated fatty acids of membrane phospholipids (Slater et al., 1985). These findings may explain the cause of necrosis, which was observed in the present study.

In the current experiment ,restraint stress produced very harmful effects which damaged the liver cells and caused a degree of degeneration in hepatocytes. The cells became vacuolated. The vacuoles progressed to necrosis; these damaging effects of stress were reduced by ginseng administration. These results agreed with the findings of Yoshikawa et al., (1998) and Sikiric et al., (1993) who studied the effects of glycosidic fraction from the dried roots of Panax ginseng. They proved that this extract has hepatoprotective effects. It prevented the development of liver necrosis or fatty changes in rats subjected to restraint stress.

In conclusion the lipid accumulation in the hepatocytes in restraint stress was attenuated or almost prevented by the administration of Ginseng. Ginseng has definite hepatoprotective properties and may prevent fatty degeneration of the liver.

It is advisable that people subjected to chronic stress must be given ginseng root extract.

\section{References}

1. Alptekin, N; Seckin, S. and Uysal, M: Lipid peroxides and glutathione activity in several tissues of rats following water- imersion stress. Pharmacolpes 1996, 34:167-9.

2. Capel, ID; Dorrell, HM; and Smallwood, AE: The influence of cold restraint stress on some component of the antioxidant defense system in the tissues of various ages. J.Toxicol.Environ. Health, 11: 425-36, 1983.

3. Caso,M.A;

Vargas,R.R;Salas,V.A and Begona,I.C: double blind study of a multivitamine complex supplemen ted with Ginseng extract.Drugs under Experimental \& Clinical Research . 72(6):324-9,1996.

4. Ceremuzynski, L; Barcikowski, B; and Herbaczynskacedrio, B: Stress induced injury of pig myocardium is accompanied by increased lipid peroxidation and depletion of mitochondrial ATP. Exp.Pathol., 43: 213-20, 1991.

5. Huong, NTT; Matsumoto, K; and Watanabe, $\mathrm{H}$ : Crude saponin extracted from Vietnamese giseng and its major consituent majon oside-R2 attenuate the psycholo gical stress- and foot-shock stressinduced antinociception in mice. Phar. Bioch. and Behavior, 52 (2): 427-32, 1995.

6. Nguyen, M. D; Nguyen, T. N. and Yamasaki, K: Saponins from Vietnamese Ginseng, Chem.Pharm. Bull,(Tokyo)41,2010-2014,1993.

7. Seckin, S; Alptekin, N; and Uysal, M: The effect of chronic stress on hepatic and gastric lipid peroxidation in long-term depletion of glutathione in rats. Pharm res, 36 (1): 55-57, 1997.

8. Sikiric, P; Grabarevic, Z; and Petek, M: Hepatoprotective effect of Panax ginseng root extract on liver lesions induced by either restraint stress or bile duct and hepatic artery 
ligation. Life-Sci., 53 (18): PL 2916, 1993.

9. Simmons, HF; James, RC; Harbison, RD; and Robert, SM: Depression of glutathione by cold restraint in mice. Toxicology, 161: 59-71, 1990.

10. Stater, TF; Cheesman, KH; and Davis, MJ: Free radicals in liver injury. Poli, G; Cheesman, KH; and Stater, TF (Eds), 197-215. IRL press, Oxford, Washington. 1985.

11. Sudo,S.and Miki,C.J.:Effect of majonoside-R2 on gastric lesion in psychologically stressed mice . PharmacologyBiochemistry\&Behav iour 53(4):957-63,1996.

12. Takahashi, M; Tokuyama, S; and Kaneto, $\mathrm{H}$ : Distinctive implication of emotional factors in various types of stress- induced analgesia. Jpn. J. pharmacol, 4: 41820, 1988.

13. Yegen, B; Dedeoglu, A; and Yalcin, S: Effects of cold -restraint on glutathione and lipid peroxide levels in the liver and glandular stomach of rats. Pharmacol. Res., 22:45-8, 1990.

14. Yoshikawa, M; Murakami, T; and Yashiro, K: Bioactive saponins and glycosides from the dried root of Panax Ginseng .Chem.Pharm.Bull.(Tokyo),45(6):10 39-45, 1997.

15. Yoshikawa, M; Murakami, T; and Yashiro, K: Bioactive saponins and glycosides from American panax ginseng roots. Chem-PharmBull , Tokyo, 46(4): 647-54, 1998.

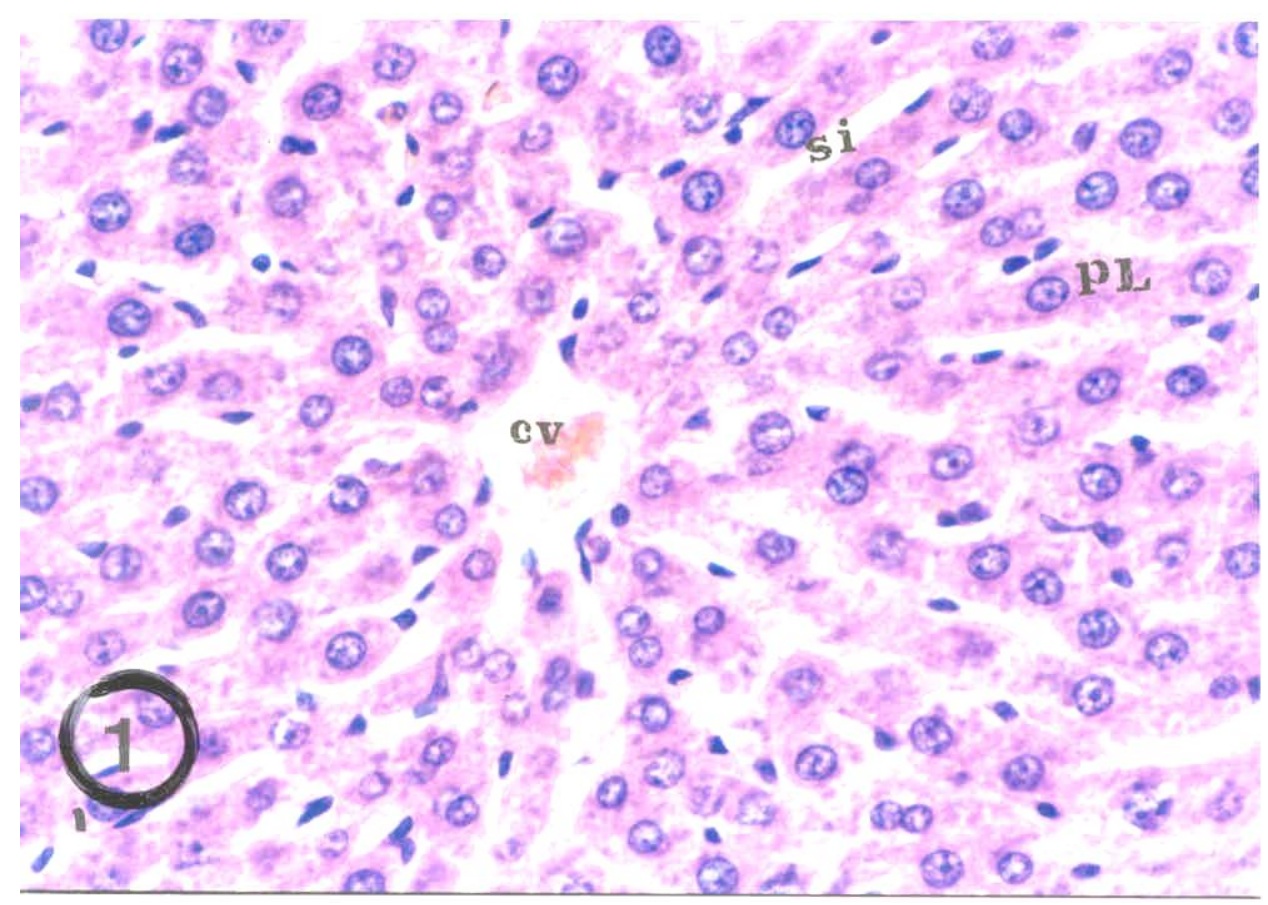

Fig.(1) :

A photomicrograph of a section of the liver of control group showing plates of liver cells ( $\mathrm{pl})$ and sinusoids ( $\mathrm{si})$.Notice the central vein $(\mathrm{CV})$.

(H\&EX400) 


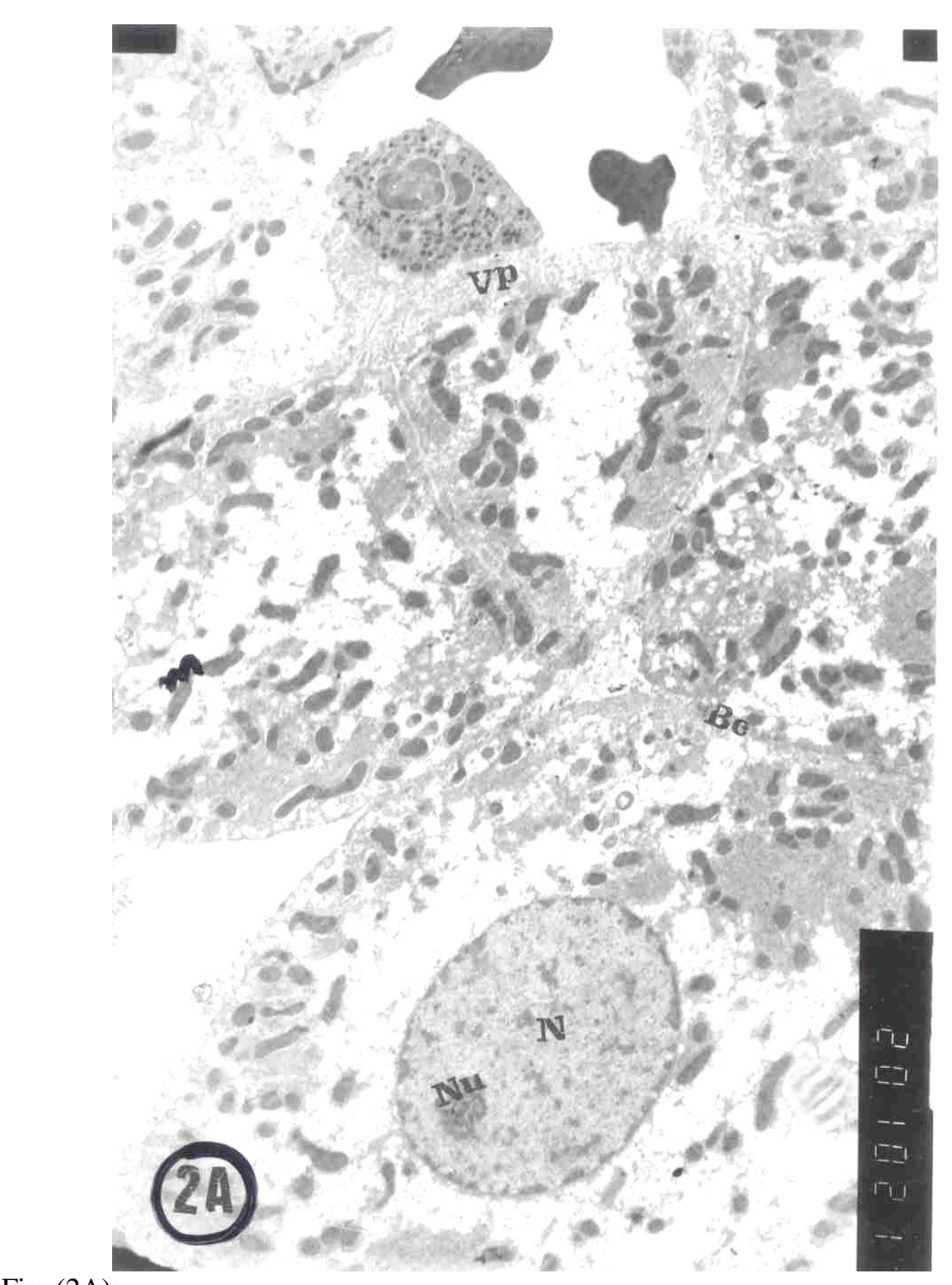

Fig .(2A):

EM of liver of control group showing nucleus $(\mathrm{N})$ of hepatocyte with prominent nucleolus $(\mathrm{Nu})$. The cytoplasm is rich in mitochodria $(\mathrm{m})$ and rER Note the bile canlliculus (BC) and the vascular pole (VP) of the hepatocyte.

(X 2000) 


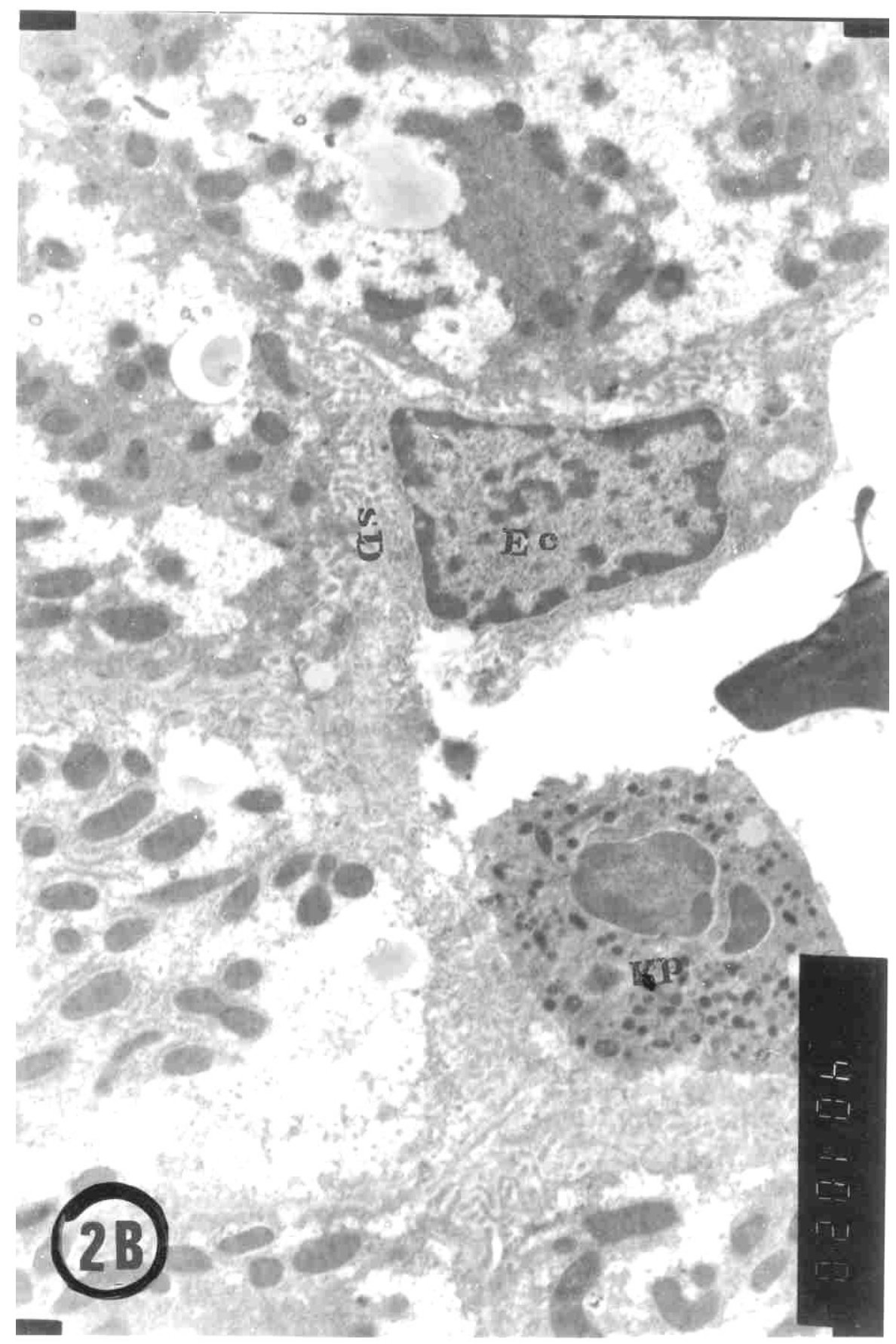

Fig (2B):

Higher magnification view showing endothelial cell (EC) and kupffer cell (KC) bulging into the sinusoidal lumen .Notice the space of Diss (D).

$(\mathrm{X} 4000)$ 


\section{Effect of "Ginseng" administration}

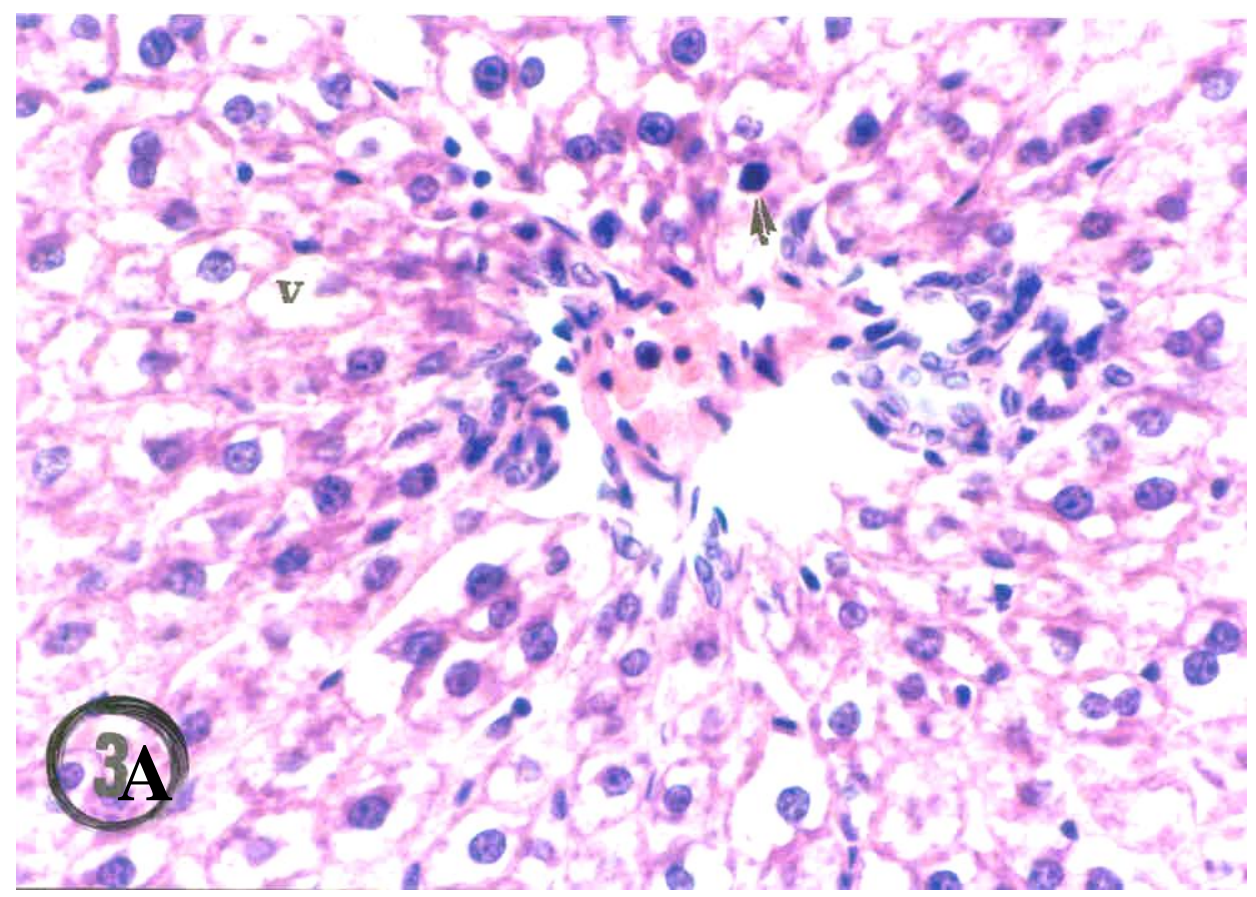

Fig. (3A):

A photomicrograph of a section of liver of stress group showing marked vacuolation $(\mathrm{V})$ of hepatocytes at the periphery of the lobule. Notice a necrotic cell $(\uparrow)$.

$(\mathrm{H} \& \mathrm{EX} 400)$

Fig.(3B):

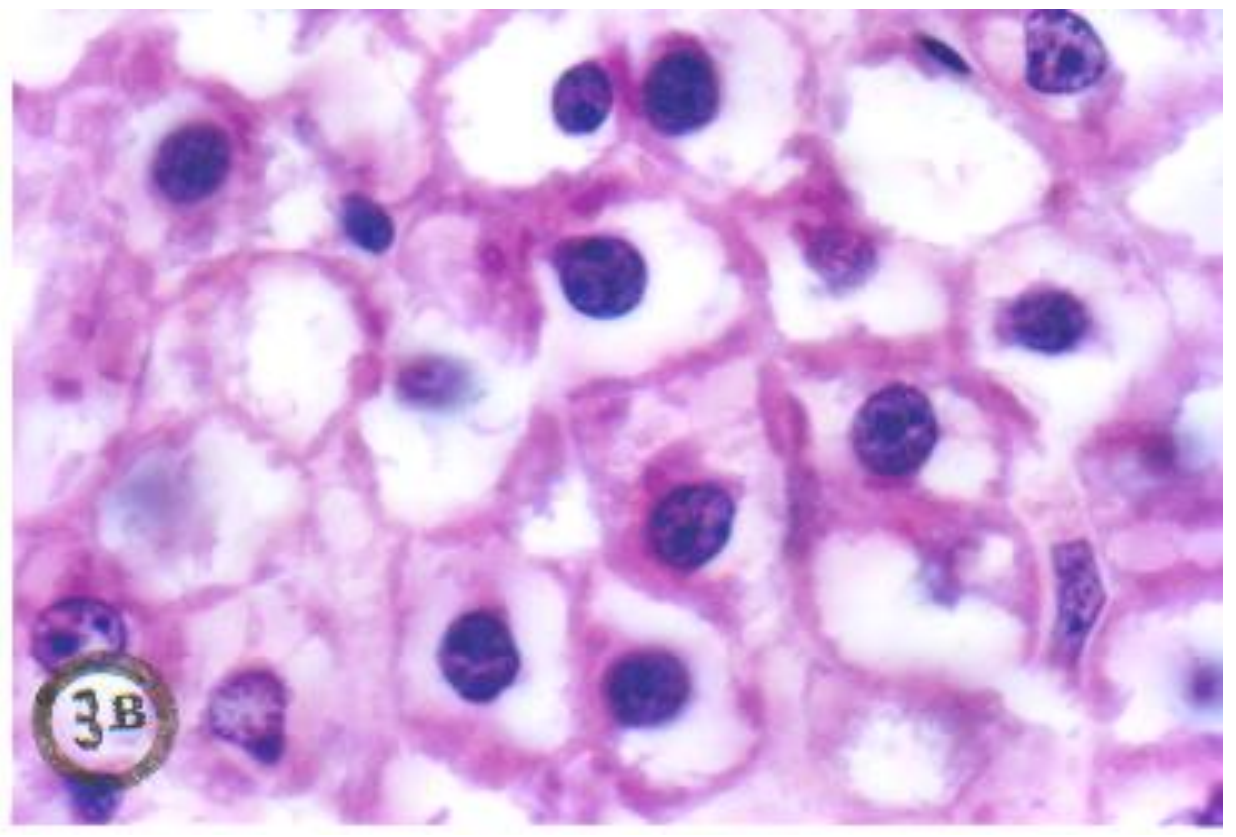

Higher magnification of part of the previous section showing markedly vacuolated hepatocyte.

(H\&EX1000) 


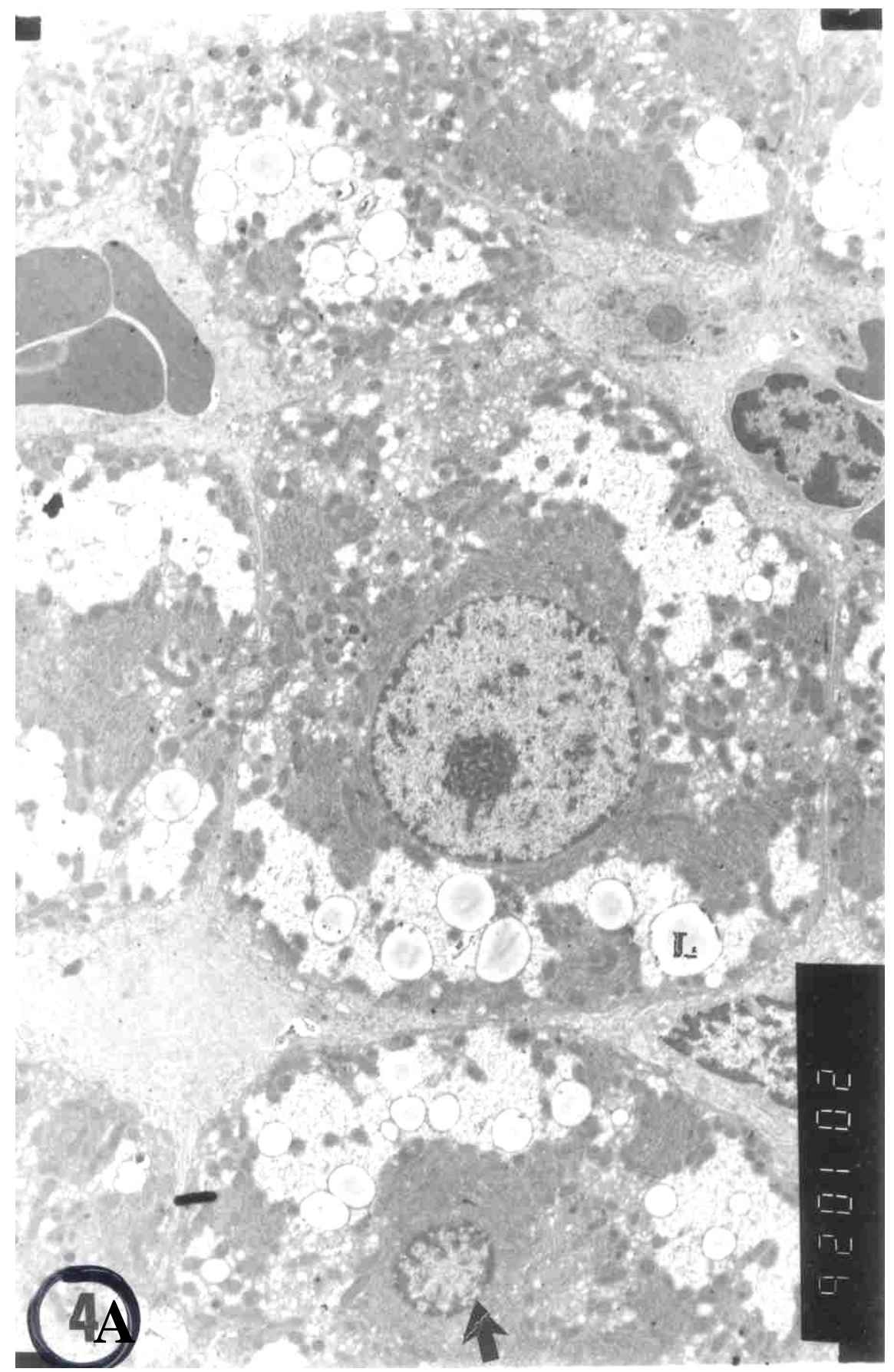

Fig. (4A):

EM of liver of stress group showing a hepatocyte with normal nucleus. Notice the lipid droplets (L) seen in its cytoplasm. Notice the small nucleus of necrotic cell with clumping of its chromatin $(\uparrow)$.

(X2000) 


\section{Effect of "Ginseng" administration}

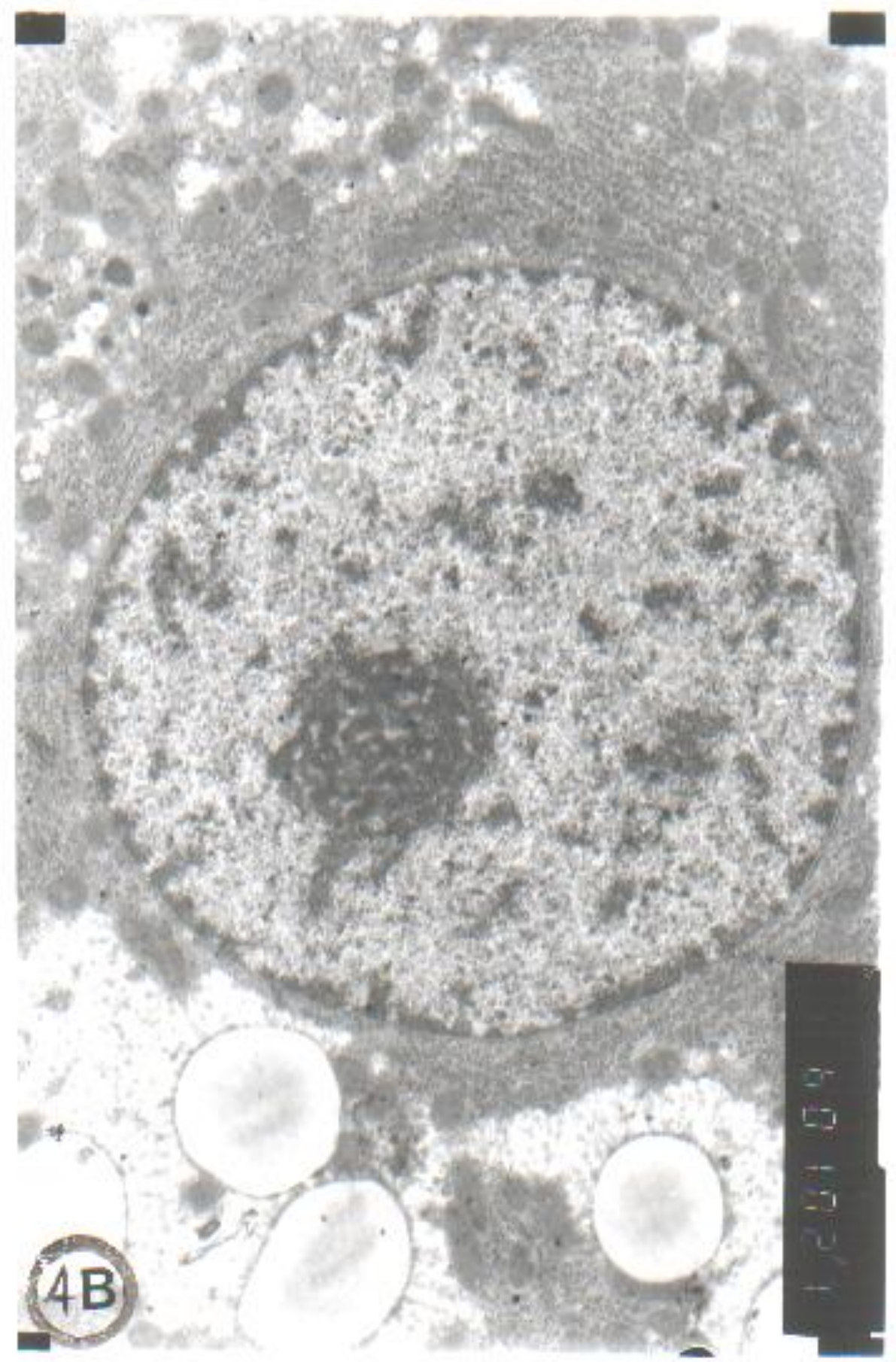

Fig.(4B):

Higher magnification of part of the previous micrograph.

(X6000) 


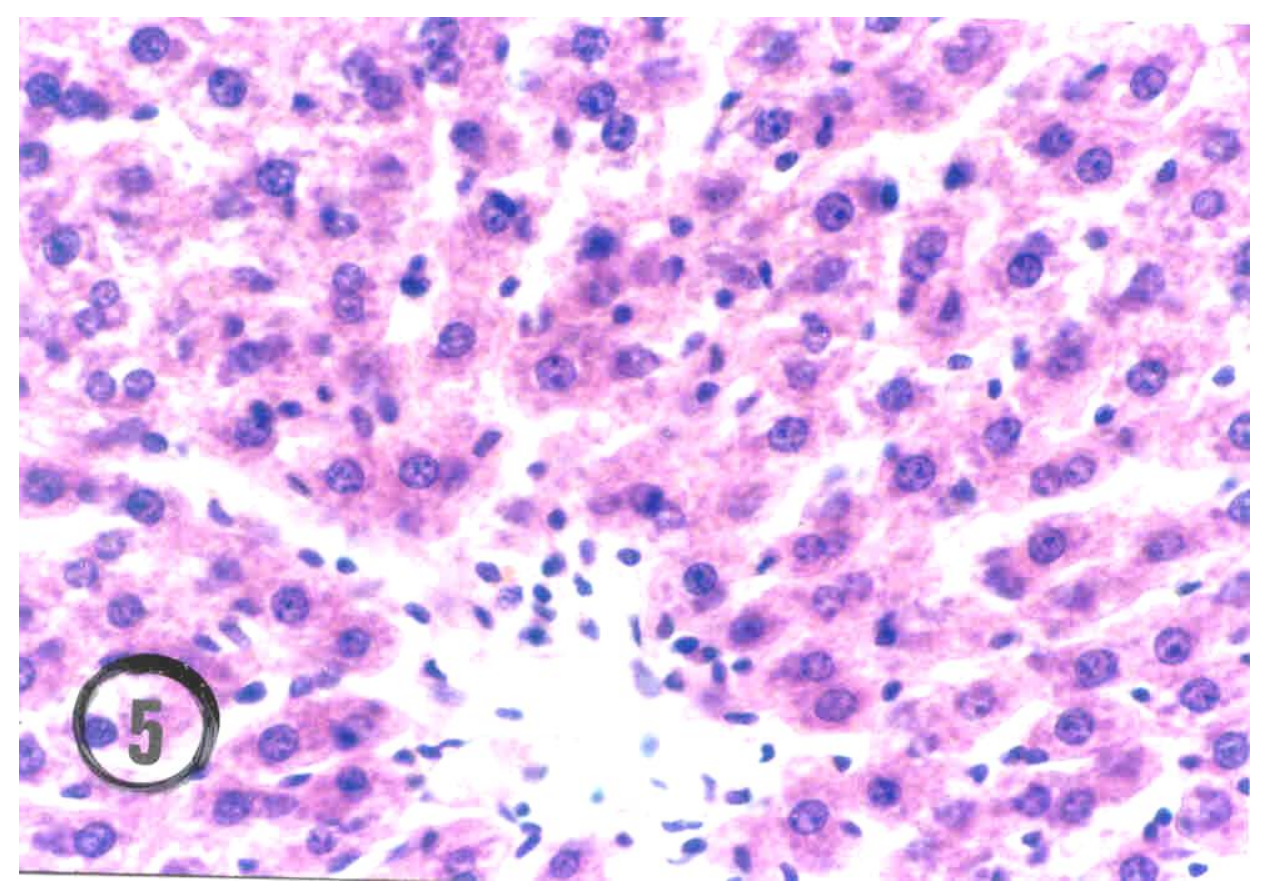

Fig. (5):

A photomicrograph of a section of liver of stress/ginseng group showing more or less normal hepatocyte.

(H\&EX400)

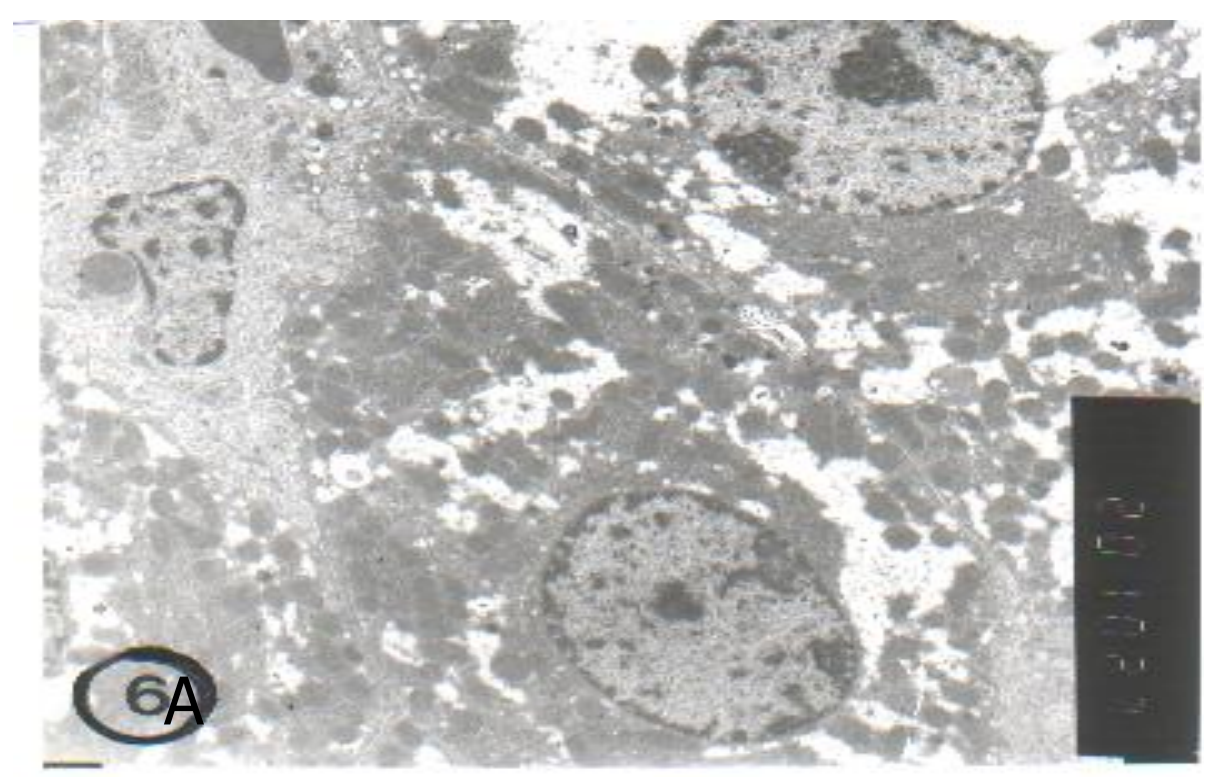

Fig.(6A):

EM of liver of stress/ginseng group showing more or less normal hepatocytes.

(X4000) 


\section{Effect of "Ginseng" administration}

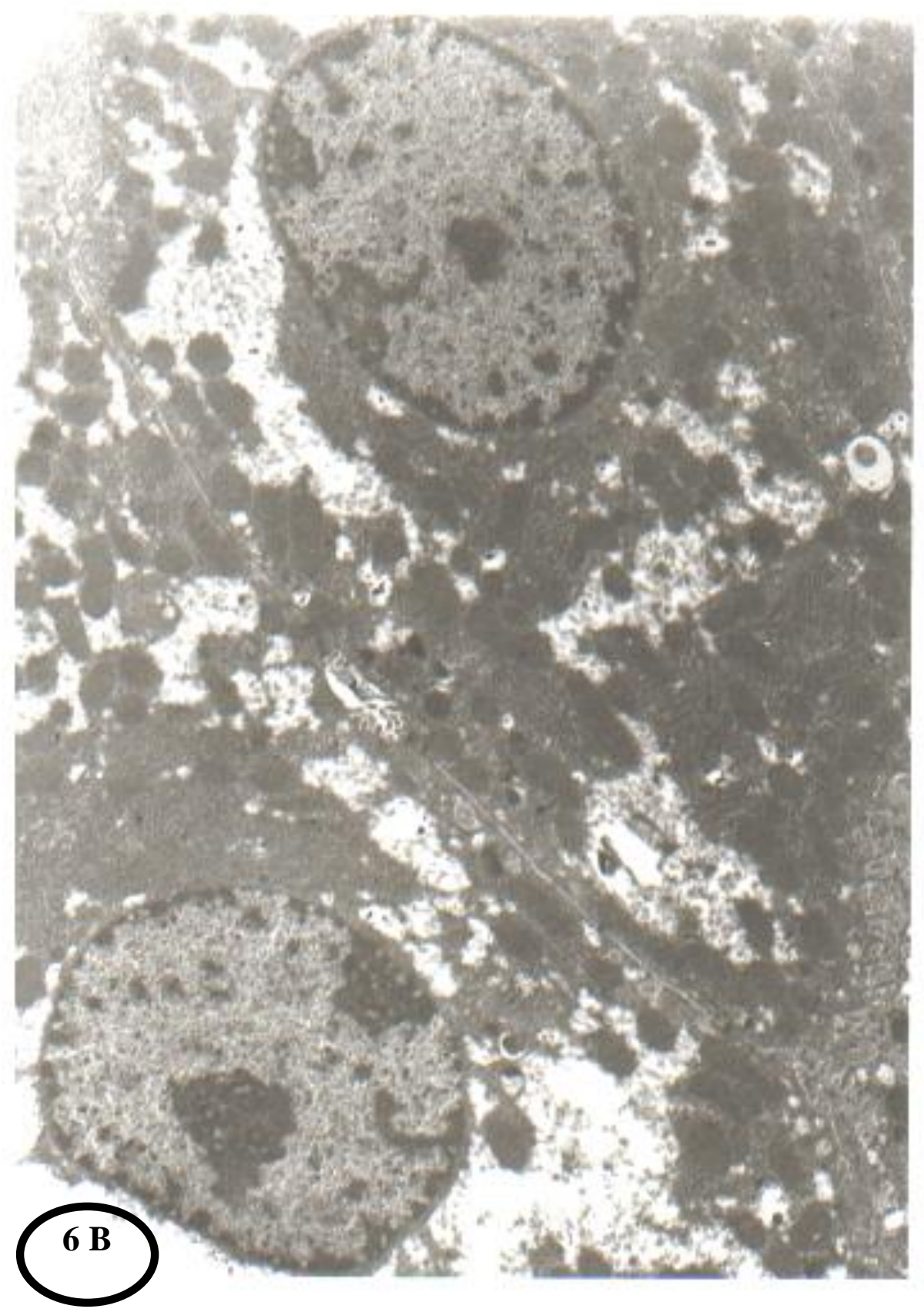

Fig.(6 B ):

Higher magnification of part of the previous micrograph . 
تأثير تعاطي الجنسنج علي التغير في التركيب و التركيب الدقيق لخلايا كبد الفئران البيضاء عتيجة الإجهاد بتقيد الحركة التركي

\author{
مني عبد الرحمن سالم \\ قسم الهستولوجي كلية الطب (بنات) جامعة الاز هر لر مر
}

تهذف هذه الدراسة الي تحديد تأثير الجنسنج المضاد للاجهاد في حالات الاجهاد

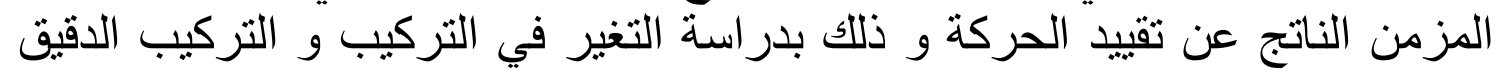

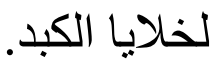

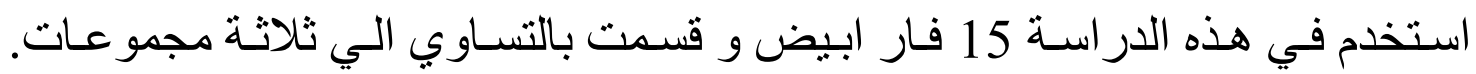

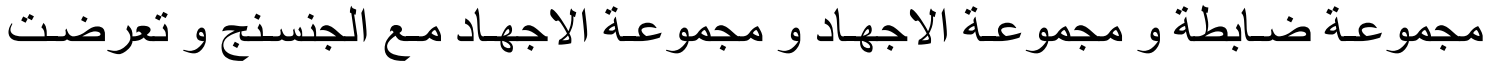

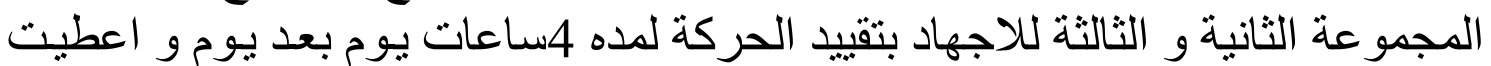

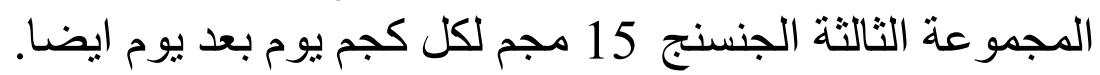

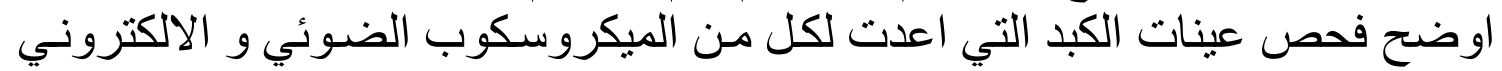

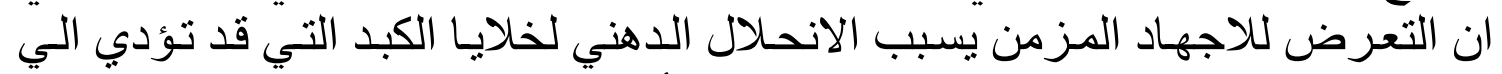
موت الخلايا. وقد لوحظ ان تعاطي الجنسنج له تأثير وقائي علي الأني الكبد. 